\title{
Trapezoid Bone
}

National Cancer Institute

\section{Source}

National Cancer Institute. Trapezoid Bone. NCI Thesaurus. Code C12859.

A carpal bone located between the trapezium and capitate bones. 